\title{
Image-Based 3D Modeling as a Documentation Method for Zooarchaeological Remains in Waste-Related Contexts
}

Stella Macheridis

Author Address: Department of Archaeology and Ancient History, Lund University, Box 192, 22100 Lund, Sweden.

Email: stella.macheridis@ark.lu.se

Received: February 7, 2015

Volume: $6(2): 242-248$

Published: December 18, 2015

(C) 2015 Society of Ethnobiology

Abstract: During the last twenty years archaeology has experienced a technological revolution that spans scientific achievements and day-to-day practices. The tools and methods from this digital change have also strongly impacted archaeology. Image-based 3D modeling is becoming more common when documenting archaeological features but is still not implemented as standard in field excavation projects. When it comes to integrating zooarchaeological perspectives in the interpretational process in the field, this type of documentation is a powerful tool, especially regarding visualization related to reconstruction and resolution. Also, with the implementation of image-based 3D modeling, the use of digital documentation in the field has been proven to be time- and cost effective (e.g., De Reu et al. 2014; De Reu et al. 2013; Dellepiane et al. 2013; Verhoeven et al. 2012). Few studies have been published on the digital documentation of faunal remains in archaeological contexts. As a case study, the excavation of the infill of a clay bin from building 102 in the Neolithic settlement of Çatalhöyük is presented. Alongside traditional documentation, infill was photographed in sequence at each second centimeter of soil removal. The photographs were processed with Agisoft Photoscan. Seven models were made, enabling reconstruction of the excavation of this context. This technique can be a powerful documentation tool, including recording notes of zooarchaeological significance, such as markers of taphonomic processes. An important methodological advantage in this regard is the potential to measure bones in situ in for analysis after excavation.

Keywords: Image-based 3D modeling, Field zooarchaeology, Waste-related contexts, Digital reconstruction

\section{Introduction}

This paper describes a case-study where the systematic use of image-based 3D modeling techniques was tested on faunal remains in an infill context. The aim was to evaluate the method with regard to its analytical value after excavation as well as its interpretative value in the field. The documentation of faunal remains, especially related to integration with field context information, is often left to the zooarchaeologist well after excavation. However, with image-based 3D modeling techniques the evaluation and interpretation of animal bones and their distributions in infill contexts can elucidate information and perspectives that may otherwise be overlooked. This can range from spatial linkages with other zooarchaeological materials or with features and multiple types of artifacts. By documenting infill materials in this way, new information can be provided through stepping into 3D space and by decreasing the conceptual distance between field and lab, which encourages new analytical and interpretive perspectives (Berggren et al. forthcoming; De Reu et al. 2014; cf. Hodder 1999; Katsianis et al. 2008). Additionally, the field contexts can be made more accessible for analysis and discussion in future research as well as in field settings.

The Study Site

Çatalhöyük is a well-known site in central Anatolia. Famous for, amongst other things, its architecture, wall paintings, and burials, the excavations at the site have provided intimate and unique insights into Neolithic imagery, symbolism, mentality, and behavior (e.g., Hodder 2006, 2011; Hodder and Meskell 2011; Martin and Russell 2000). The preservation of the archaeology at the site has made it excellent for the development and application of single-context excavation techniques as well as other methodological innovations. For a number of years, the ongoing research project at Çatalhöyuk has included a team of digital archaeologists experimenting and testing new approaches to further implement digital technology for site documentation. Both laser scanning and 


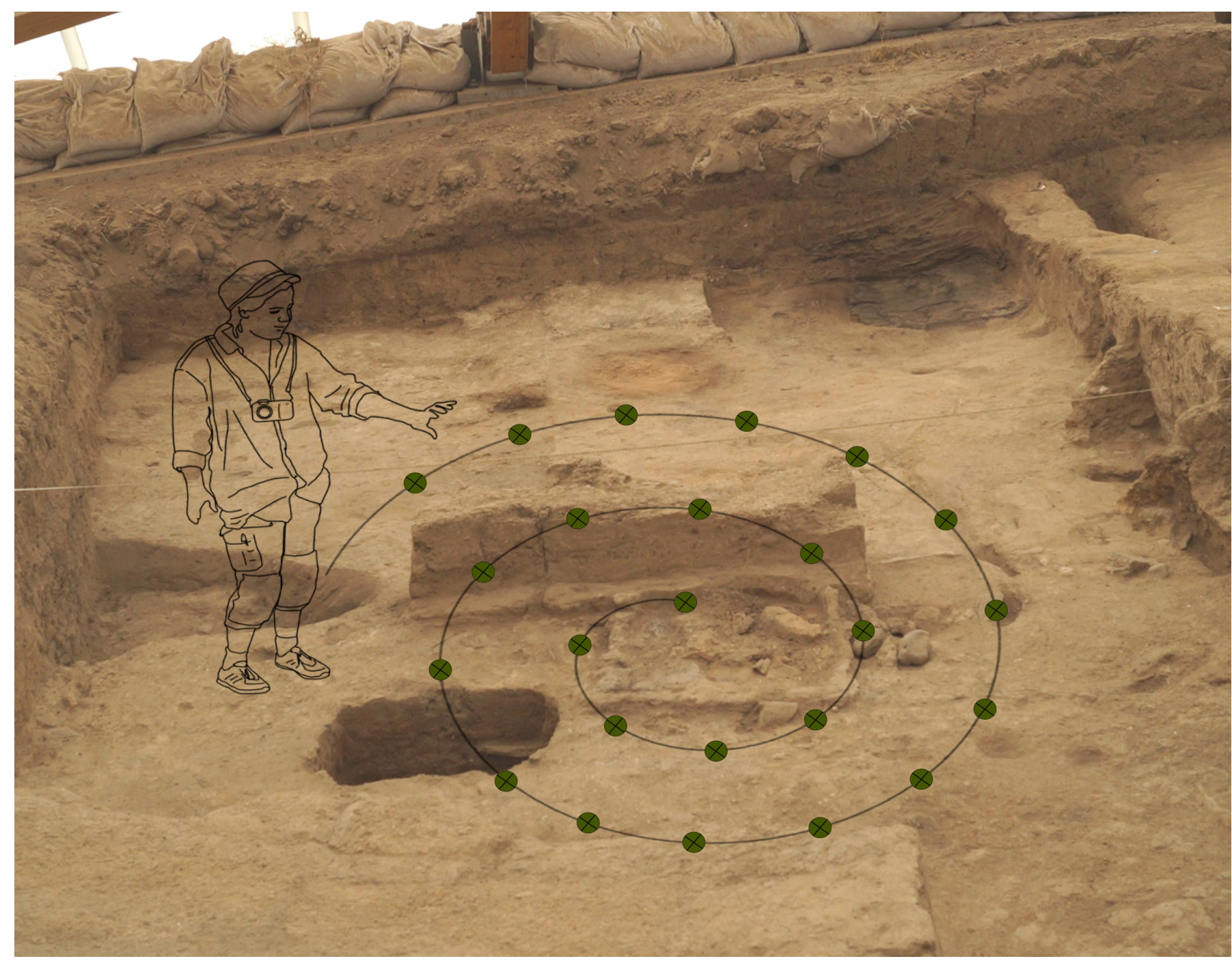

Figure 1. Spiral "route" for photographic documentation. The round X-markers represent stops in the route for taking photographs of the feature.

image-based 3D modeling are and have been used in this process (Forte et al. 2012). For example, the use of image-based 3D modeling to document human burials at the site has been evaluated and is now common practice (Knusel et al. 2013). Since 2013 all documentation has been made digitally via PC-tablets as standard procedure, providing high-resolution records of fieldwork and site contexts (Berggren et al. forthcoming; Issavi and Taylor 2014).

\section{The Case Study}

This case study presents the excavation of the infill of a clay bin (F 3698) from building 102 in the Neolithic settlement of Çatalhöyük (Tung 2013). Building 102 is located in the northern area of the site and is not fully excavated. This building was discovered in 2007 during excavations to prepare for the erection of a big shelter to cover this particular area. The clay bin infill was excavated in 2013, when excavation of the building was resumed (Tung 2013). The bin was attached to an internal wall, and its infill was documented using traditional excavation and documentation (ibid. 2013). This feature was also recorded by means of image-based 3D modeling to provide a case study exploring the utility of this particular technique. The reason that the infill of this clay bin was considered suitable for documentation by image-based 3D modeling is that it was located directly underneath a larger room and could represent closing of the final phase of the house. The generation of a $3 \mathrm{D}$ model to 


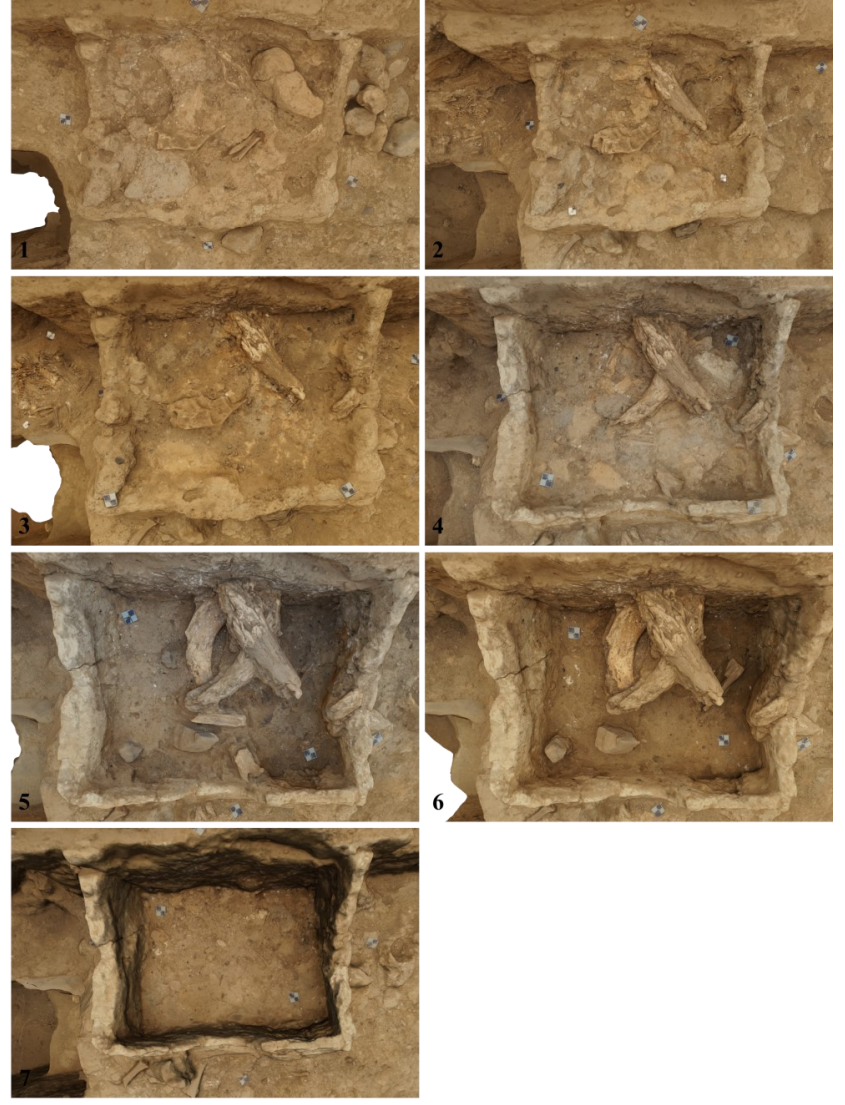

Figure 2. Sequence of seven 3D-models showing the progress of excavation. The sequence starts with the top layers of soil from the left to the right. The models are numbered from 1-7 in the bottom left corner.

display the room and the bin would illustrate the tangible and intimate connection of these two spaces. Early in the excavation it was clear that at the top of the infill layer there was a large amount of wellpreserved animal bones compared to the condition of faunal remains previously discovered in this particular house. Excavators recognized that this context provided an opportunity for a distinctive case study of how this documentation technique can be used to record spatial distributions of faunal remains in infill contexts.

\section{Methodology}

The use of Agisoft Photoscan allows the generation of detailed three-dimensional models from sets of unordered images. It cannot replace the interpretative nature of plan drawings, but it provides a 3D model that has high resolution in terms of geometry and image quality (Dell'Unto 2014). When using this technique in the field, it is important to plan the use of it beforehand. Even though application of the approach is not time-consuming, the area of interest and its close surroundings must be thoroughly cleaned and camera angles must not be changed abruptly when photographing. The use of a planned work-flow is thus highly recommended (De Reu et al. 2014; Dellepiane et al. 2013). Work-flows regarding digital technologies on a site level are being formulated and constantly tested (i.e. De Reu et al. 2014; Dellepiane et al. 2013; Katsianis et al. 2008). Also, archaeologists already photograph contexts and findings in the field, often as complements to drawings, so it takes little time to adjust and freely work with this method. This specific context was relatively sheltered from changes in light and shading, which could present a real challenge in other settings. For this case-study a system camera (Sony a58) with a preset resolution of $10 \mathrm{mp}$ was used, without use of a flash.

During the documentation of the excavation of the infill of the clay bin, some necessary steps were implemented in each set of photographs. After each second centimeter of soil removal, a series of 40-60 photographs were taken following a spirally route, illustrated in Figure 1. We also set up 4-6 ground control points within and around the context in each set of images. We documented these with a total station, as opposed to measuring the distances between them (cf. De Reu et al. 2013). This ensures that the measurements can later be correctly spatially referenced. Also, we took extra photos of particular zooarchaeological remains to ensure detailed reconstruction. For example, horn cores in the middle of the infill were considered of interest to the excavators (Figure 2).

The technicalities and steps for processing imagebased 3D modeling can be found in other works (De Reu et al. 2014; Remondino and El-Hakim 2006). Here, processing involved data extraction, meshing and scaling following Dellepiane et al. (2013:205). The software recognizes local features in the photos during data extraction by aligning the images and during calculation of the model. These photos are matched to calibrate and orient the images, resulting in a point cloud of a triangulated surface (De Reu et al. 2014; Dellepiane et al. 2013). Meshing and coloring involves matching every pixel to recreate coordination in digital three-dimensional space. The triangulated surface is filtered to reduce noise, and all gaps in the model are closed. After this process, original colors are added to the model. Scale is corrected using 
markers from the context, allowing reconstruction of physical measurements. The model can easily be transferred to the project's general coordination and spatial reference system in a GIS (De Reu et al. 2014; Dellepiane et al. 2013). The 3D models for this study were processed in Agisoft Photoscan, version 1.0.0 (Agisoft LLC 2011). Using this software it is possible to geo-reference the model using external ground control points (Agisoft LLC 2011).

\section{Results}

In this case study, I highlight the faunal remains in an infill of a clay bin in one of the Neolithic houses of Çatalhöyük. Figure 2 illustrates a sequence of seven 3D models documenting the removal of the infill in the clay bin in each excavation phase (each second centimeter). A total of 336 photographs were used to produce the models (roughly 48 images per model). Compared to traditional documentation by plan mapping, this technique reduced the time in the field as it took about ten to fifteen minutes to photograph each sequence, including clean-up. The horn cores from cattle and wild sheep in the middle of the bin were reconstructed in detail in the model. The actual horn cores became fragmented when lifted from the soil but may, according to the excavators, represent the remains of something placed carefully within the bin (Tung 2013). However, the horn cores could simply be infill material, such as refuse. The interpretation of the horn cores was refined by reconstructing the context at the same time as the next layer of soil was removed. Their clear placement on top of each other is probably due to a conscious act, either during the usage phase or right before deposition (see Tung 2013). The model is detailed, and might be useful in the future when reviewing the last phase of use and later the infilling of the house.

\section{Discussion}

Mapping the precise contextual locations of faunal remains by hand is Sisyphean in terms of work effort. As illustrated in this case study, 3D-modeling enables re-assessment of context because any notes and maps detailing the recovery of faunal specimens can be reconsidered by returning to the model where the remains are documented in high resolution. Digital approaches to archaeological documentation can potentially enable more detailed examination of spatial patterning even after remains have been removed from their excavation contexts. For example, as reported in this study, spatial patterning of
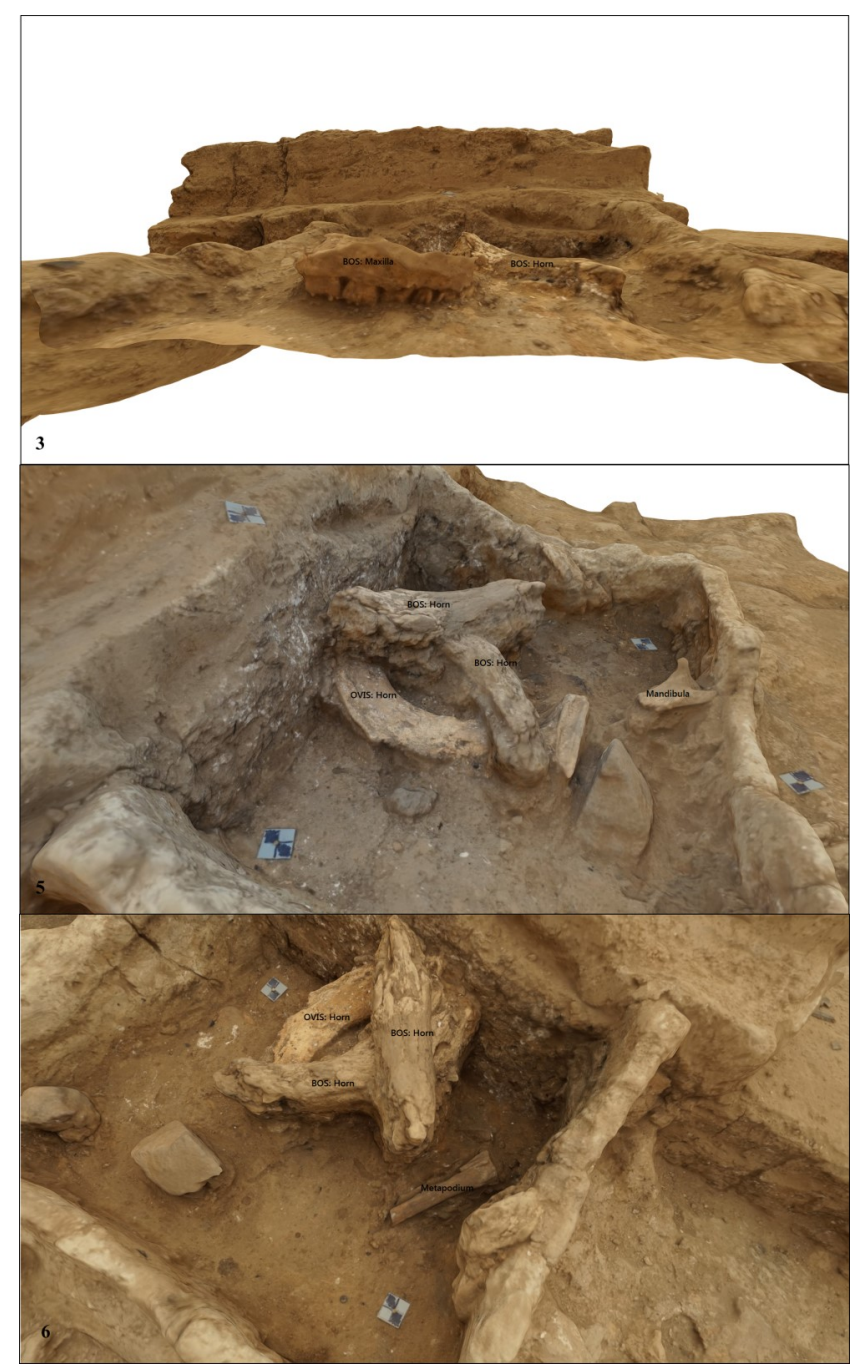

Figure 3. Close-up snapshots from the models. The numbers in the top left corner indicate from which models they were taken in figure 2 .

faunal remains in infill contexts, where materials might be considered "waste" provides a basis for research concerning waste and refuse disposal patterns (see Martin and Russell 2000). These concepts are not only important in a taphonomic sense, but also in discussions of cultural/ritual behavior (i.e. Hill 1995; Marciniak 2005; Orton 2012; Thilderqvist 2013). This type of analysis can be strengthened by the photographic documentation approach presented in this study.

More generally, research within virtual reality and the use of 3D modeling in archaeology holds great potential. In recent years, virtual collections as well as studies on osteometry and morphological differences 
in 3D have been established (Betts et al. 2011; Macane 2012; Niven et al. 2009; Smith and Strait 2008). One advantage of 3D modeling in zooarchaeology is an ability to measure faunal remains during excavation for purposes of analysis later. While this has been noted in this study, to argue for the continued implementation of image-based 3D modeling in field zooarchaeology, an evaluation of the accuracy and precision of measurements derived from 3D models is needed. This holds potential for producing new zooarchaeological knowledge since measurable bones can experience heavy erosion and breakage during excavation and curation, which may depend on the preservation condition of bone as well as environmental factors. An experiment focusing on what can be better preserved through application of 3D modeling would benefit the further development and implementation of such approaches in zooarchaeology.

Image-based 3D modeling can be useful as a detailed reconstruction technique of refuse contexts in which faunal remains are often abundant. The reconstruction can be of high value for field interpretation by archaeologists. Compared to burials, infill layers are often not given the same degree of detailed documentation. In this sense 3D modeling makes it possible to return to the context to make spatial connections and associations among archaeological materials. 3D models can potentially be integrated with GIS and spatial analyses of faunal remains to investigate possible clustering of remains for particular taxa or types of skeletal parts (Berggren et al. 2015). Similarly, such models may be used to investigate taphonomic histories of faunas.

Depending on the resolution desired, the time needed to generate models will differ. This might disturb the flow of the excavation (De Reu et al. 2014). The amount of time needed to generate models will surely decrease with the growing capacity of computers and software. Despite the many advantages, image-based 3D modeling should not completely replace other interpretive documentation methods, such as plan drawings, context description, and field journals (De Reu et al. 2013; Dell'Unto 2014). The analytical value of the $3 \mathrm{D}$ model decreases greatly if other types of documentation are disregarded. For example, in this case study the model would be of no interpretive value if not connected to the field situation and the interpretations of the excavators.
A formal guideline or practical handbook of image-based 3D modeling techniques is missing in archaeology, although Dellepiane et al. (2013) have described a functioning workflow. English Heritage has also produced a practical guide for laser scanning techniques within cultural heritage studies (English Heritage 2011). For zooarchaeologists, it would be useful to have handbooks on image-based 3D modeling techniques, with guidelines regarding faunal remains in various archaeological situations, such as the documentation of animal burials and other ritual remains.

\section{Conclusions}

This short paper has reviewed the use of image-based 3D modeling as a technique for documenting zooarchaeological remains in waste-related depositional contexts. As previously established, image-based 3D modeling is an effective tool in terms of time- and cost-effectiveness in the field. Although 3D modeling should not be considered a replacement for traditional field documentation methods, it provides a higher resolution and visualization in three-dimensional space. With a thorough field assessment of taphonomic markers and other zooarchaeologically significant indicators, this technique can provide a good foundation for research on spatial association of artifacts and features, waste management, and the use of bone within living quarters. One great methodological advantage of this technique for the zooarchaeologist is an ability to measure bones during excavation for analysis later. Despite these advantages, it would be helpful to have a set of guidelines for image-based 3D modeling in zooarchaeology, which should incorporate basic osteology, zooarchaeological methods, and taphonomy.

\section{Acknowledgements}

I am grateful to the Çatalhöyük Research Project and its director Ian Hodder for the opportunity to conduct this experiment. Also, I wish to acknowledge my colleagues in the field and the staff at the site for help and encouragement. I am thankful to Niccolo Dell'Unto for help with technical issues as well as providing thoughtful comments on earlier drafts.

\section{Declarations}

Permissions: Not applicable.

Sources of Funding: Funding for electronic devices was provided by Helge Ax:son Johnsons stiftelse. Travel expenses were funded by Längmanska Kulturfonden.

Conflicts of Interest: None declared. 


\section{References Cited}

Agisoft, LLC. 2011. Agisoft Photoscan User Manual, Professional Edition, version 1.0.0: Agisoft LLC. Available at: http://downloads.agisoft.ru/pdf/ photoscan-pro_1_0_0_en.pdf.

Berggren, A., N. Dell'Unto, M. Forte, S. D. Haddow, I. Hodder, J. Issavi, N. Lercari, C. Mazzucato, A. Mickel, and J. S. Taylor. forthcoming. Revisiting Reflexive Archaeology at Çatalhöyük: Integrating Digital and 3D Technologies at the Trowel's Edge. Antiquity 89:433-448.

Betts, M. W., H. D. G. Maschner, C. D. Schou, R. Schlader, J. Holmes, N. Clement, and M. Smuin. 2011. Virtual Zooarchaeology: Building a Webbased Reference Collection of Northern Vertebrates for Archaeofaunal Research and Education. Journal Of Archaeological Science 38:755-762. Doi 10.1016/ j.jas.2010.06.021.

De Reu, J., P. De Smedt, D. Herremans, M. Van Meirvenne, P. Laloo, and W. De Clercq. 2014. On Introducing an Image-based 3D Reconstruction Method in Archaeological Excavation Practice. Journal Of Archaeological Science 41:251-262. Doi 10.1016/j.jas.2013.08.020.

De Reu, J., G. Plets, G. Verhoeven, P. De Smedt, M. Bats, B. Cherrette, W. De Maeyer, J. Deconynck, D. Herremans, P. Laloo, M. Van Meirvenne, and W. De Clercq. 2013. Towards a Three-Dimensional Cost-Effective Registration of the Archaeological Heritage. Journal Of Archaeological Science 40:11081121. Doi 10.1016/j.jas.2012.08.040.

Dell'Unto, N. 2014. The use of 3D models for intrasite investigation in archaeology. In 3D Recording and Modelling in Archaeology and Cultural Heritage: Theory and best practices, BAR International Series, edited by F. Remondino and S. Campana, pp. 151-158. Archaeopress, Oxford.

Dellepiane, M., N. Dell'Unto, M. Callieri, S. Lindgren, and R. Scopigno. 2013. Archeological Excavation monitoring Using Dense Stereo Matching Techniques. Journal of Cultural Heritage 14:201-210. Doi 10.1016/j.culher.2012.01.011.

English Heritage, 2011. 3D Laser Scanning for Heritage: Advice and Guidance to Users on Laser Scanning in Archaeology and Architecture, Second edition: English Heritage. Available at: http:// www.english-heritage.org.uk/publications/3d-laser-
scanning-heritage2/3D_Laser_Scanning_final_lowres.pdf. Accessed on October 12, 2014.

Forte, M., N. Dell'Unto, J. Issavi, L. Onsurez, and N. Lercari. 2012. 3D Archaeology at Çatalhöyük. International Journal of Heritage in the Digital Era 1:351378.

Hill, J. D. 1995. Ritual and Rubbish in the Iron Age of Wessex: A Study on the Formation of a Specific Archaeological Record. British Archaeological Report, Oxford.

Hodder, I. 1999. The Archaeological Process: An Introduction. Blackwell Publishers, Oxford.

Hodder, I. 2006. The Leopard's Tale: Revealing the Mysteries of Catalhöyïk. Thames \& Hudson, London.

Hodder, I. 2011. Human-Thing Entanglement: Towards an Integrated Archaeological Perspective. Journal of the Royal Anthropological Institute 17:154-177. Doi 10.1111/j.1467-9655.2010.01674.x.

Hodder, I., and L. Meskell. 2011. A "Curious and Sometimes a Trifle Macabre Artistry" Some Aspects of Symbolism in Neolithic Turkey. Current Anthropology 52:235-263. Doi 10.1086/659250.

Issavi, J., and J. S. Taylor. 2014. Tablet Recording Overview. In Catalböynk 2014 Archive Report. Çatalhöyuk Research Project. Available at: http:// www.catalhoyuk.com/downloads/

Archive_Report_2014.pdf.

Katsianis, M., S. Tsipidis, K. Kotsakis, and A. Kousoulakou. 2008. A 3D Digital Workflow for Archaeological Intra-Site Research Using GIS. Journal Of Archaeological Science 35:655-667. Doi 10.1016/j.jas.2007.06.002.

Knusel, C. J., S. D. Haddow, J. W. Sadvari, and N. Dell'unto. 2013. Bioarchaeology in 3D: Employing Three-Dimensional Technology in the Field and in the Lab. American Journal Of Physical Anthropology 150:170-171.

Lyman, R. L. 1994. Vertebrate Taphonomy. Cambridge Manuals in Archaeology. Cambridge University Press, Cambridge.

Macane, A. 2012. Fusing Osteology with Virtual Reality: Three Dimensional Morphological Differences between Harp Seal (Pagophilus groenlandicus) and Ringed Seal (Phoca hispida), Department of Archaeology and Ancient History, Lund, http:/lup.lub.lu.se/ student-papers/record/2545039. 
Marciniak, A. 2005. Placing Animals in the Neolithic: Social Zooarchaeology of Prehistoric Farming Communities. UCL Press, London.

Martin, L., and N. Russell. 2000. Trashing rubbish. In Towards Reflexive Method in Archaeology: The Example at Catalhöyük, British Institute of Archaeology at Ankara Monograph, edited by I. Hodder, pp. 57-69. McDonald Institute for Archaeology Research, Cambridge.

Niven, L., T. E. Steele, H. Finke, T. Gernat, and J. J. Hublin. 2009. Virtual Skeletons: Using a Structured Light Scanner to Create a 3D Faunal Comparative Collection. Journal of Archaeological Science 36:20182023. Doi 10.1016/j.jas.2009.05.021.

Orton, D. C. 2012. Taphonomy and Interpretation: An Analytical Framework for Social Zooarchaeology. International Journal of Osteoarchaeology 22:320-337. Doi 10.1002/Oa.1212.

Remondino, F., and S. El-Hakim. 2006. Image-Based 3D Modelling: A Review. Photogrammetric Record 21:269-291.

Smith, N. E., and S. G. Strait. 2008. PaleoView3D:
From Specimen to Online Digital model. Palaeontologia Electronica 11.

Thilderqvist, J. 2013. Ritual Bones or Common Waste: a Study of Early Medieval Bone Deposits in Northern Europe. Barkhuis \& Univerisity of Groeningen, Groeningen.

Tung, B. 2013. Excavations in the North Area, 2013. In Çatalhöyük 2013 Archive Report. Çatalhöyük Research Project. Available at: www.catalhoyuk.com/downloads/ Archive_Report_2013.pdf.

Verhoeven, G., M. Doneus, C. Briese, and F. Vermeulen. 2012. Mapping by Matching: A Computer Vision-Based Approach to Fast and Accurate Georeferencing of Archaeological Aerial Photographs. Journal Of Archaeological Science 39:2060-2070. Doi 10.1016/j.jas.2012.02.022.

\section{Biosketch}

Stella Macheridis is a PhD candidate in Historical Osteology, Department of Archaeology and Ancient History. 